\title{
A Study and Overview of the Mobile App Development Industry
}

\author{
Thomas C. G. ${ }^{1}$ \& A. Jayanthila Devi ${ }^{2}$ \\ ${ }^{1}$ Research Scholar, College of Computer Science and Information Science, Srinivas \\ University, Mangalore, Karnataka, India and Assistant Professor, Dept. of IT, AIMIT, St. \\ Aloysius College, Beeri, Mangalore, Karnataka, India \\ Orc ID: 0000-0002-1955-0251; E-mail: jothomas13@gmail.com \\ ${ }^{2}$ Professor, College of Computer Science \& Information Science, Srinivas University, \\ Mangalore - 575001, India. \\ ORCID: 0000-0002-6023-3899; Email: jayanthilamca@ gmail.com
}

Subject Area: Information Technology.

Type of the Paper: Research Case Study.

Type of Review: Peer Reviewed as per $|\mathrm{C}| \mathrm{O}|\mathrm{P}| \mathrm{E} \mid$ guidance.

Indexed In: OpenAIRE.

DOI: http://doi.org/10.5281/zenodo.4966320

Google Scholar Citation: IJAEML

\section{How to Cite this Paper:}

Thomas, C. G., \& Jayanthila Devi, A., (2021). A Study and Overview of the Mobile App Development Industry. International Journal of Applied Engineering and Management Letters (IJAEML), 5(1), 115-130. DOI: http://doi.org/10.5281/zenodo.4966320.

International Journal of Applied Engineering and Management Letters (IJAEML)

A Refereed International Journal of Srinivas University, India.

Crossref DOI : https://doi.org/10.47992/IJAEML.2581.7000.0097

(C) With Authors.

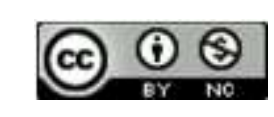

This work is licensed under a Creative Commons Attribution-Non-Commercial 4.0 International License subject to proper citation to the publication source of the work.

Disclaimer: The scholarly papers as reviewed and published by the Srinivas Publications (S.P.), India are the views and opinions of their respective authors and are not the views or opinions of the S.P. The S.P. disclaims of any harm or loss caused due to the published content to any party. 


\title{
A Study and Overview of the Mobile App Development Industry
}

\author{
Thomas C. G. ${ }^{1}$ \& A. Jayanthila Devi ${ }^{2}$ \\ ${ }^{1}$ Research Scholar, College of Computer Science and Information Science, Srinivas \\ University, Mangalore, Karnataka, India and Assistant Professor, Dept. of IT, AIMIT, St. \\ Aloysius College, Beeri, Mangalore, Karnataka, India \\ Orc ID: 0000-0002-1955-0251; E-mail: jothomas13@ gmail.com \\ ${ }^{2}$ Professor, College of Computer Science \& Information Science, Srinivas University, \\ Mangalore - 575001, India. \\ ORCID: 0000-0002-6023-3899; Email: jayanthilamca@ gmail.com
}

\begin{abstract}
Background/Purpose: We are in an era where a lot of disruptive technologies that change the entire perspective of the market are arriving very often. One such is the emergence of Mobile App Development, which completely changed the way users utilized software. Even though software development generally meant a stand-alone or Web application in the past, now it has enormous space given to Mobile App Development. Standalone technologies demanded the user to have a Personal Computer at least, with them to utilize their applications. However, since the platform on which an app can be deployed is just a mobile phone, the target audience for this type of application development becomes manifold. App development that targets handheld devices has now become a standard by which services reach the target audience faster since almost everyone has access to a mobile device. The App Development industry has only grown in leaps and bounds ever since its inception. This paper discusses in detail the Mobile App Development Industry and its predominance in India.

Objectives: To analyse and understand the Mobile App Development Industry worldwide and in India, to understand the preference, usage, revenue, cost, and scope of App Development in India and to perform a SWOC Analysis for the Mobile App Development Industry.

Design/Methodology/Approach: A detailed analysis of the Mobile App Development Industry is done by various secondary data sources such as websites and blogs. Some Scholarly research articles are also referred to understand the challenges in the industry.

Findings/Result: Based on the SWOC Analysis of the Mobile App Development Industry, we can say that this industry is going to be one of the most sought-after industries especially in a pandemic-stricken world.
\end{abstract}

Originality/Value: This paper, analyses various aspects of the Mobile App Development Industry. Based on the analysis, the current and future state of the industry is presented.

Paper Type: A research case study paper on the Mobile App Development Industry.

Keywords: Mobile App Development, Android, iOS, Industry Analysis, App Development Industry, App Development Companies

\section{INTRODUCTION :}

In the Industry of Information Technology, a variety of software have been changing the way we look at things from the dawn of its era. We see that almost every other process we have been doing manually is now done and monitored by systems. Software Development is an industry that comes under this parent and is a general term used in developing and deploying software that is in the category of websites and standalone applications. While creating these applications, the minimum hardware requirements given were typically a personal computer with adequate specifications. In the age of software, people who could afford and own a computer were only able to use or utilize it. Till a particular time, people accessed websites only through Cyber Cafes. Now even though many have access to laptops and PC's, the count remained significantly low compared to the population. After 
mobile phones were introduced, which were typically a hand-held computer, the number of people who started buying mobile phones is significantly higher and the number of people who can get an idea of applications started getting multiplied. Today we can say that irrespective of which age group they belong to, people are learning to use an application in the form of a Mobile App. The App Development Industry has taken advantage of it ever since.

\section{OBJECTIVES :}

- To understand the App Development Industry in general.

- To analyse the App Development Industry in India.

- To understand the Usage of Mobile Apps and Revenue generated.

- To understand the cost and scope of App Development in India Compared to others.

- To study the various types of apps in demand and the least preferred apps.

- To perform a SWOC analysis for the App Development Industry.

\section{METHODOLOGY :}

The information presented and analysed in this paper are mostly based on Secondary Data obtained from different online sources such as Websites, Journals, Internet Blogs and Articles, Discussions, Books etc.

\section{MOBILE APP DEVELOPMENT OVERVIEW :}

Mobile App Development is the process by which software that primarily runs on a handheld digital device such as a Mobile Phone is developed. It is an ever-growing industry that is now an integral part of any business we can think about. Even though there is a variety of mobile phones available in the market, Android and iOS take the major chunk. Let us see the Mobile OS Market share throughout the world:

Table 1: Mobile Operating System Market Share Worldwide - March 2021 [1]

\begin{tabular}{|c|l|c|}
\hline S.No. & \multicolumn{1}{|c|}{ Mobile Operating System } & Percentage \\
\hline 1 & Android & $71.81 \%$ \\
\hline 2 & iOS & $27.43 \%$ \\
\hline 3 & Samsung & $0.38 \%$ \\
\hline 4 & KaiOS & $0.14 \%$ \\
\hline 5 & Unknown & $0.14 \%$ \\
\hline 6 & Linux & $0.02 \%$ \\
\hline
\end{tabular}

With this sort of market people generally look for development of Mobile Apps in Android and iOS, which makes up $99.24 \%$ of the global market currently. Even though Android takes up $96.07 \%$ in India, iOS takes the lead in the US by having $59.97 \%$ [2]. So, the App Development industry majorly focuses on these two Operating Systems as their target. Even though traditional software development is still viable, App Development supersedes them by providing features that a typical desktop or web application may fail to provide. For example, the availability of GPS, Compass, Accelerometer, Sensors, Bluetooth etc. makes the Mobile Phone a much powerful deployment device than a PC.

While developing a Mobile App, just like how typical software would be developed, we need to choose a programming language and/or an appropriate framework [3]. Even though we might see Android and iOS development individually, it is essential to see the various types of Mobile App Development available [4]. There are Three Major Types of App Development, they are:

\subsection{Native App Development}

Native App Development is where a developer creates an app by targeting a particular platform like Android or iOS. It supports all the features that the OS provides and also allows us to utilize the maximum potential of a mobile device [5]. It provides far superior performance than any other types of app development [6]. In order to develop an Android app, developers use Android Studio as the official 
IDE and Java or Kotlin as the languages through which they create apps. Whereas, iOS developers use XCode and Objective-C or Swift as their languages to develop apps [7]. The Native App development has its own advantages and disadvantages. Let us see them in brief:

\section{Advantages:}

- Provides Faster and Efficient Performance since it targets only one OS

- They are more efficient in utilizing the resources that the mobile device has to offer.

- It can take advantage of all the hardware features of a phone such as Bluetooth, NFC, Sensors, Camera etc.

- Provides a Secure, Robust and interactive platform specific user interface.

\section{Disadvantages:}

- Since it targets only one platform, the same app needed in another needs to be created from the scratch.

- Native App Development demands the knowledge of Mark-up and Programming Languages for more complex-natured apps.

- The cost of development will go higher since two different sets of codes need to be created to guarantee the app to be available in both platforms [8]

\subsection{Web App / Html5 Development}

Web apps are simply websites that provide the look and feel of an actual responsive website. They are generally written using HTML5, CSS and JavaScript and run in a browser. Installing such an app just means we are creating a bookmark to this page and calling that link an app. Since they are responsive, they will adjust themselves according to whichever device screen size they are called on. Compared to the native app development, they are limited in their functionality and inferior in performance. Developing a Web App is typically developing a website, so the technologies needed are HTML5, CSS, JavaScript on the Client Side and PHP, Perl, Python Ruby, etc. and other server-side technologies [9].

\section{Advantages:}

- No need to target a particular platform, so once developed, it can be deployed on any platform.

- Since there is nothing to download onto the mobile, little to no storage is utilized.

- Maintaining the app becomes easier since any changes or updates are automatically pushed through the web, so no need for any updates.

\section{Disadvantages:}

- Since it is completely dependent on the browser, the user experience might differ based on the user's choice for a browser.

- Since they are basically websites, they won't work without the internet.

- You cannot take advantage of all the features a mobile device has to offer.

- Unavailable at the play store, and so adding or installing it to a phone needs special instructions or promotions to actually reach a user [8].

\subsection{Hybrid App Development}

Hybrid apps are half native apps and half web-apps. They can be distributed through an app store and take advantage of some of the native features too [10]. Since they are web apps too, they depend on HTML that gets presented in a browser. Even though they look and feel like a native app, they would still be a simple web app running on a browser and hence the name hybrid app. It helps the developers to reach a larger target audience and monitor how many people downloaded their apps, etc. without bothering about developing two different apps [11]. There is a variety of ways in which we can develop a hybrid app, some of which are React Native, Flutter, Cordova, Ionic, Xamarin, etc.

Advantages:

- Much Faster to Develop and more economical compared to native app development. 
- Need to maintain only one code base that will update simultaneously into any platform that is targeted.

- Can be made available even offline.

- Best to make an MVP (the Most Viable Product) immediately available through an app.

\section{Disadvantages:}

- Cannot be used to develop performance-centric apps like games that need to utilize the 3D features

- Performance is much lesser than native apps since they are limited by Web View.

- Not so optimal in UI since the User Experience cannot be customized [8]

Even though there are a lot of apps currently in the market which use a combination of the abovementioned types of development, each app is developed in a particular type by taking a few points into consideration like Cost of Development, Time Taken, Features needed, and a lot of more customized choice. The industry of app development has grown so tremendously worldwide, and it is continuing to do so every day. This market had its value as \$106.27 Billion in 2018 and is expected to reach $\$ 407.31$ Billion by the year 2026 [12]. Apart from the revenue generated through the app, the development industry also needs to be spoken about. The charge to develop a typical app depends on a lot of factors, and there cannot be a fixed price. However, we can keep the development cost for a simple app between 15 to 25 thousand in USD and a medium complex app to be between 40 to 100 thousand in USD. The app development industry continues to grow since the need for apps is always on the rise.

\section{APP DEVELOPMENT INDUSTRY IN INDIA :}

The progressive Policy Institute of the United States in a report released in 2019 said that India, as one of the premier technology-centric countries in the world, would surpass the US in the largest developer population hub by the year 2024 [13]. According to that report, India is one of the leading countries in mobile app downloads with more than 500 million users of smartphones. This is sufficient to comprehend the state of India in the realm of apps and app development. India has progressed by leaps and bounds in the areas of App Development, and one cannot deny that. In the past few years, apps developed by Indian App Developers are being hosted in the Google Play Store and Apple App Store [14]. Let us see what are the trends and factors that are the main reason for India to have the largest developer population in the world:

\subsection{Dawn Of $5 \mathrm{~g}$ Network:}

$5 \mathrm{G}$ is the latest addition to an array of network technologies which allows high-speed with 0-Latency. In the ever-demanding technology world, the speed of the Internet plays a very vital role. From a time where data was charged for each KB used, we now have practically unlimited supply of data in handheld devices. While there is a huge difference between the internet, we get via broadband at home and in our mobile data, 5G will be the equalizer [15]. The data will not be standing in the way of downloading and using Data Heavy Applications.

\subsection{Wearable Apps \& Others for The Medical Industry:}

The area of app development has not just stopped with mobile devices and tabs and has rather extended to cater to apps that need to be installed in wearable devices such as watches, body monitoring devices etc. which mostly help people and health care workers. Agriculture and Health Care Industries are something which cannot be ignored at any cost [15]. The development of apps that help to monitor a person's heartbeat and other vitals, also to monitor how many steps taken, calories burnt, etc. There are a lot of health-conscious people who are looking forward to monitoring themselves with the wearable. It can also support doctors and nurses in monitoring patients who are not able to report these things and are in quarantine at home or health centres.

\subsection{M-Commerce:}

e-Commerce has become m-Commerce with the majority of the orders placed via an app. Some major e-commerce industries give a lot of offers to people who prefer to order through an app rather than 
through the website, so that they can bring in notifications and future offers quickly to the attention of the customer [15]. The biggest fear for a user was the payment for these orders placed on online platforms. It has been now diluted by various payment modes that are currently in the market starting from Cash on Delivery, Credit Cards, Debit Cards, Net banking and even UPI-based payments. There are all-in-one stores and category specific stores in app mode that facilitate users to buy whatever they want in a few clicks.

\subsection{IoT:}

Even though IoT might not be technically known to many, people understand the need for devices that are used on a constant basis becoming smarter by the day [15]. From the angle of app development, it is to create an app that currently helps with home-automation like controlling speakers, TV, Cameras, $\mathrm{AC}$, etc. As we progress in this field, we see the development of apps not just for home and entertainment purposes, we see more apps with features that could control equipment in factories, offices or even vehicles. It is inevitable in the future to provide apps that take advantage of the IoT.

\subsection{Cloud-Based Apps:}

Nowadays, most of the users' data are not stored on a local device but rather are stored on specialized and dedicated servers on the cloud to give uniform experience to the user across devices [16]. The features that a user is currently looking for in a phone are ease of access and usage across various platforms, security, storage and processing of the data to obtain information or insight. While the majority of storages are on the cloud, the user gets the data and information needed without bothering about the hardware or configuration of the device he or she is accessing the app from [17]. App developers now target these kinds of apps that take advantage of the cloud services, and it has been a huge improvement over the traditional apps.

\section{MOBILE APP DEVELOPMENT LIFE CYCLE :}

In recent times, it is very evident that people consume digital media majorly on a mobile phone and apps take up $90 \%$ of the time spent on a mobile phone apart from using it for calls and SMS. The development of a Mobile App is not as fancy as it looks. We have already seen the various types of App Development possible [18]. Now let us look at the App Development Life Cycle of a typical mobile application project irrespective of the complexity of the app being developed [18]:

\subsection{Mobile App Objectives and Requirements}

Setting the objectives of creating an app is a crucial part of the development where the customer aims on putting objectives that the app must be able to satisfy. This phase also makes sure that the complete technical and non-technical requirements of that app are noted down clearly [5]. This phase makes the developer understand the problem statement clearly and have overall understanding of the requirements of the customer [19]. For example, we must be able to answer questions like the following so to speak:

- Who are the target audiences / end users of this app?

- What is the purpose of developing this app?

- What will be benefit for the developer/company upon building this app?

- What are the technologies and tools that we might need to do this app?

- Who are the competitors in the market and what will be the Unique Selling Point (USP) of this app?

These are just a few of the questions we need to be able to answer at the end of the First Stage. It is also essential to look for a possibility where this app can be updated and be able to deliver more service as the company or area grows. Most of the time it is the vision for the future that makes an app successful because it needs to stand the test of time itself in a world where today's latest technology can be a legacy technology tomorrow.

\subsection{App Design and Prototyping}

Once the objectives of the app are clearly stated, it becomes clear what the app will be delivering. In the next step of development, we should be able to design a prototype [17] and form a storyboard. In this phase we need to focus on the functionality that is expected from the app and also the User Interface. 
The UI part is where we design what the users will see and interact with and give functionality. It is how the user will be using the app. In order to develop a working prototype of the user interface, the common thing to do is wireframing. Wireframing is a way in which we can design a skeleton of our app. Developers use it to understand the functionality of the app better and designers use it to understand the process of UI design [20]. Wireframing can be broken down into three different portions - they are:

I. Information Design:

In this part of wireframing, the focus is on where to present, place and prioritize relevant information in such a way that it helps the user in understanding [20]. It is basically part of UI Design where the information is displayed in such a way that it makes way for clear communication.

II. Navigation Design:

In this phase, wireframing creates a navigation system that gives a set of user screens which normally decides which page to be shown next based on the context and operations done in one screen [20]. There must be a clear relation between each screen and its links so that the user understands how to navigate through the app for various features.

\section{Interface Design:}

This phase of wireframing includes designing an interface where a user selects or types data via UI elements such as Text Boxes, Check Boxes, Radio Buttons, etc [20]. It makes sure that the app provides maximum usability and performs as efficiently as possible.

After the wireframing is done, it needs to go through peer-review and undergo all the changes and suggestions given by the team members or customers. Once this is approved, the next phase can begin. It is easier to change a wireframe rather than changing a complete app in development.

\subsection{Choosing a Backend:}

Every app will need to store data, but where it is stored depends on the type of data, cost and effectiveness of the storage environment. Normally, users can store data in the memory of the phone itself either in a key-value pair of data stored typically in an XML format or even in a Relational Database like SQLite. But in case the data needs to persist across users and devices, then using a Web Server would be the optimal choice [21]. That choice has multiple variants based on the requirement such as using a custom server, using a cloud server or using an MBaaS (Mobile Backend as a Service)

I. Custom Server:

We can host the data in a relational database or a NoSQL DB in the company's own server, that makes sure that the data stays within the organization but available anywhere via an API call. Scaling and optimizing might be a challenge in this way [22].

\section{Cloud Server:}

Cloud Servers come in various sizes and shapes for users to choose from like Amazon Web Services, Google App Engine etc. Data is stored in these cloud servers and are available from

III. MBaaS: anywhere via a service call and is highly scalable and optimized [22].

It is one of the most recent and popular options that is available as the fastest growing way of delivering data in cloud services. Choosing a particular type of MBaaS, finally is the choice and preference of the developer and what he or she wants to achieve through the app. It is especially helpful to scale our backend in case we target both iOS and Android Apps. For ex.: Kumulos, Progress Kinvey and Kii [22].

\subsection{Development of the App:}

Once the first two stages are done successfully, there will be a clear picture of what is needed and how it must be done. The next stage would be to start building the app with the learnings that were done in the initial planning, designing and lessons learnt. The developer/company can then choose what kind of a development environment that they would like to develop in [23]. There are different choices based on the target of the app. For Ex. If the app targets only Android users, then development of the Android app using Android Studio with Java or Kotlin will be done. If they are only iOS users, then development of that iOS app will be done using XCode with Swift or Objective C. If it is Cross-Platform, then there are other options like Hybrid Apps with No-Code or Low-Code Development [24]. 
While this stage is the longest of all, there is a high chance of finding practical issues in getting a particular functionality, or there may even be new ideas arising that was not covered in the previous two stages. Here the Business Logic of the App Development plays a major role since the prototype only gives a clear representation of the Design and Layout of the app not the actual functionality code that needs to be written at this stage [25]. If a complex app has to be built, it is better to use Agile Methodology that gives flexibility in planning, progressive development and improving it constantly.

\subsection{Testing and Quality Assurance:}

Once the app with all of its functionalities is completed, it is essential that we test the app continuously in order to find any and all bugs that the app might have. The app should be rigorously tested with a lot of real-world scenarios to figure out any technical faults that the app has. It is always recommended that the team that does testing is not the same team that built the app since there is a high chance of overlooking from their end. There might be more issues and insights that the development team might not be able to find to be obvious to them [26]. Only when the team is confident that the app satisfies all the requirements stated and is able to handle any scenario given, then the app moves to the next phase.

\subsection{Publishing:}

Releasing the app depends on the platforms where we need the users to officially get a copy of the app. It might be the Google Play Store or the Apple App Store, they would have their own process of testing the app. Once that is done successfully, the app is officially released and people can start downloading the app into their mobile devices [27]. Prior to this stage, the team will have decided how much and how to charge the user like Single Purchase, Freemium, Subscription, etc. Based on the host, a publishing cost will be charged and/or a transaction fee for each download.

\subsection{Maintenance:}

The last stage is the constant maintenance of that app after the initial release that actually makes this a Life Cycle. There might be some scenarios or issues that was overlooked in the testing phase and now being pointed out by users and also to make sure that the app works smoothly over the period of hardware and software changes. Failing this stage makes the app irrelevant after a while, and it is vital that as long as the app is needed, developers should monitor the apps vigour and serviceability.

\section{USAGE OF MOBILE APPS :}

The number of mobile apps that are currently in the market are growing by the day, and people who download apps on various devices are also growing exponentially [28]. That is because currently an average adult is so much glued to the mobile, he/she owns, that is quite evident nowadays while we see others using mobile phones constantly. The mobile App Industry will keep growing till we have people who consume it, which will only keep increasing for the foreseeable future [29]. Below is the graph that shows Mobile App Downloads globally from 2016 to 2020. This graph shows us that the number in billions just keeps increasing year by year [30].

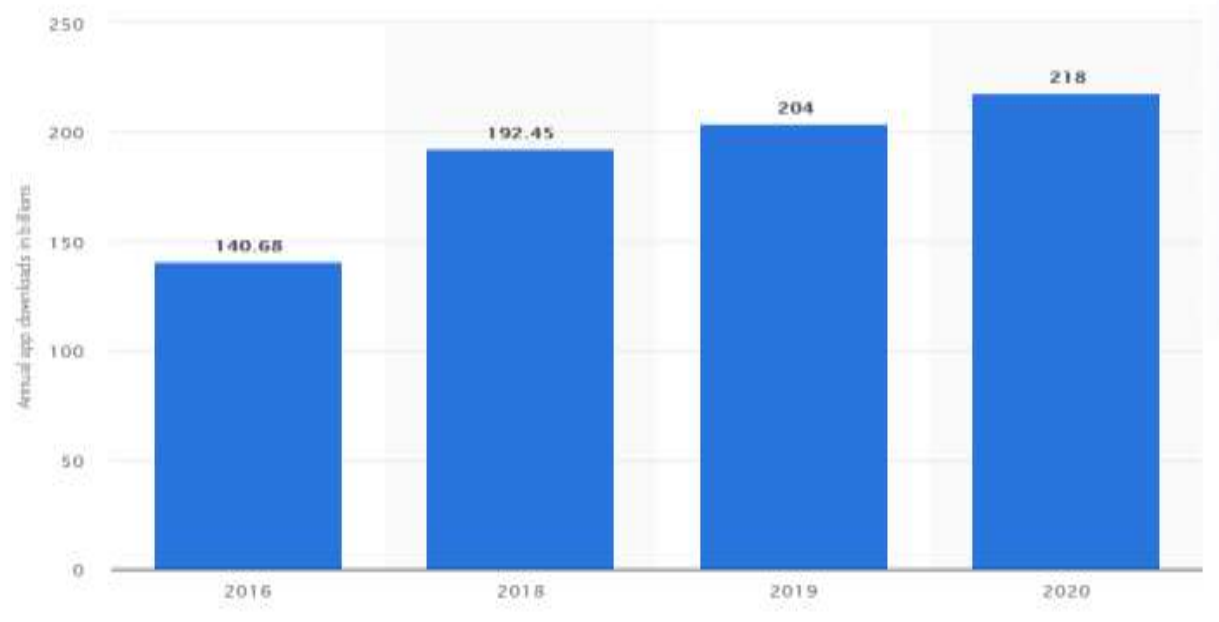

Fig 1: Number of App Downloads Globally from 2016 to 2020 
A vast majority of the apps are available as free downloads in both the major app stores, which makes users hesitant on paying for app downloads [31]. The usage of apps has started gaining popularity globally by social networking and chatting apps. We can see a clear picture of the penetration rate of a particular category of apps in Android and Apple App Stores [32]. For instance, we can determine the achievement of an app category in Android based on its rate of penetration among users as depicted in the table that follows [33]:

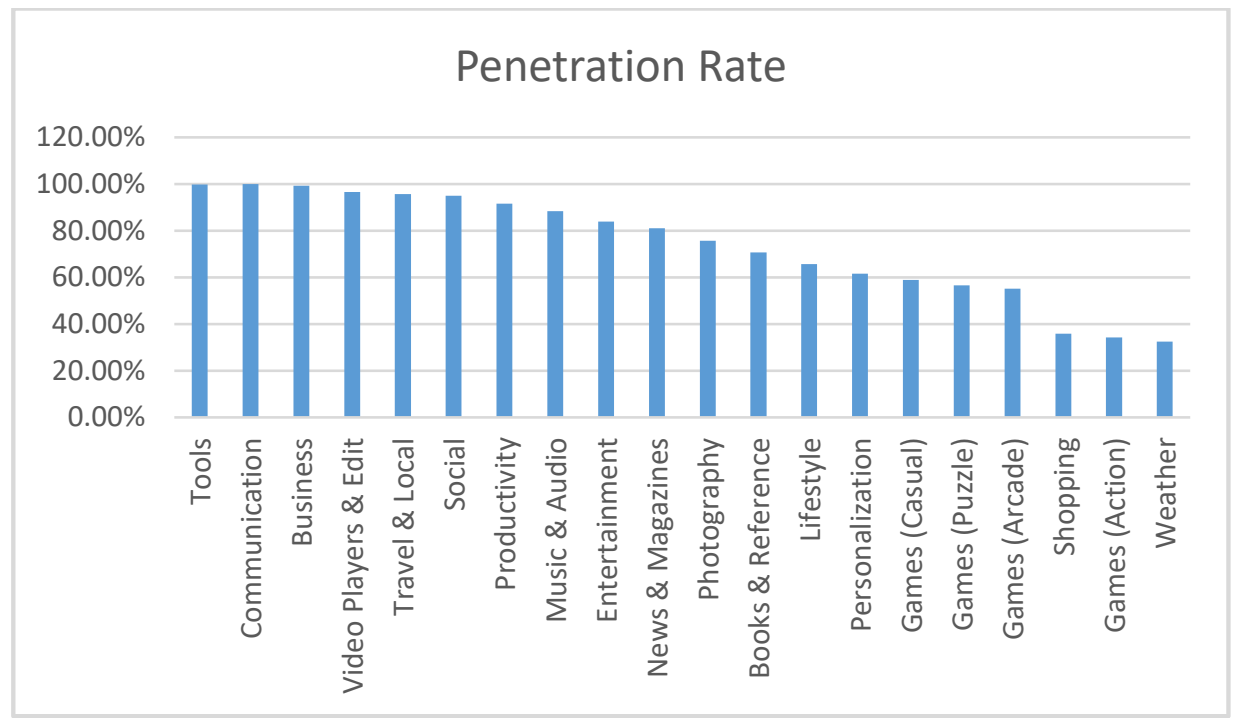

Fig 2: Penetration of Android App categories Globally as of September 2019

An average smartphone user typically spends around three hours on their phone, out of which ninety percent of the time is on the apps of the phone. Even though on an average phone there are 50+ apps installed, not many are being used often. So just because someone has downloaded an app does not mean that the user is using that app. In order to make sure that the app has a higher retention rate, the developer should be able to make the user come back to the app and keep using it for a considerable period of time. This cannot be true for each app that is on a phone. So just because people download an app does not mean that the app is great and will survive for long. It needs to be at a level where the user keeps using it and provides feedback to the developers so that the app can grow and be utilized.

\section{REVENUE GENERATION :}

The main purpose of developing apps and investing in them would be to either generate profit out of it or serve a particular society, organization or individual. Most of the times it is the former that is targeted. It is a very good source of income since the reach of the app is targeting billions of users via the App Stores. In order to figure which monetization model will be optimal for our app, it is quintessential to know the user market, so appropriate marketing efforts can be applied and also can easily forecast the revenue that can be generated [34]. Let us see an overview of the revenue generation that happens because of Apps.

\subsection{Average Revenue Per User (ARPU)}

ARPU is the total revenue that your app can generate covering all your users. It can be easily calculated using the following formula [35]:

ARPU = Total Revenue Generated in a given period / Number of Users in the Same Period

For Example, let us say that the app generated $\$ 1000$ in a particular month and there were 2000 active users during this month, then the ARPU would be $\$ 0.05$. The time period is normally calculated as months, especially the apps that have a monthly subscription model. If the app is not something that needs regular usage, then it can be quarterly, bi-annual or annual too. According to Developer Economics, the benchmark for an active user or a good ARPU is around \$0.04 per month. It fluctuates based on the industry, locale in which it is targeted, monetization model utilized, etc.

\subsection{ARPU from Apps in India}


The ARPU from apps in India is expected to increase every year for the next four years. It is said that in 2019 ARPU from apps in India was Eight Dollars per user, and it is predicted to increase to $\$ 8.50$ by the year 2023 [36]. It seems like a small number but basically it is a huge increase in the overall revenue collection from India. Let us see a graph that shows the forecast of ARPU from apps in India from 2017 to 2023:

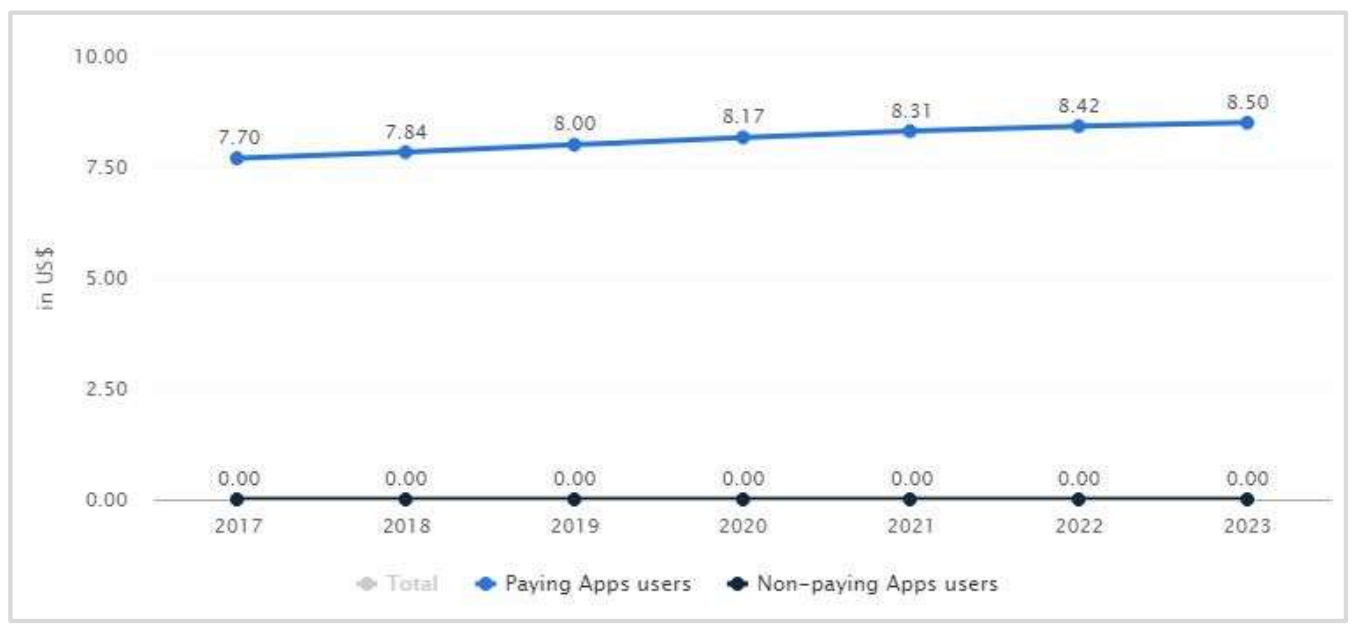

Fig 3: ARPU from Apps in India (in USD) during the forecast period 2017-2023

The graph above only shows the revenue generated by paying app users, the others do not have any contribution in it. The country which generates maximum revenue through apps is the United States of America, and the second country would be China. India is the third in that list of revenue generation through apps. Even though India comes third in that list, there is an essentially huge margin of difference between the first two countries. India is one of the fastest growing markets for apps and revenue generation through apps.

\subsection{Types of Revenue Generation Models}

The majority of the apps on the market are always targeted to make money. Rarely do people create apps that they would like to give away freely. There are a lot of ways in which a developer can generate revenue through the apps. Let us see a few predominant ones [37].

\subsubsection{In-app Advertising}

They are the most predominantly used models currently in almost all of the freely downloadable apps in the market. It is a way in which the developer gets paid for embedding ads within the app. For that the developer needs to utilize the SDK provided by the Ad Provider, and normally it is a very simple process. However, in order for this model to work, the primary requirement is to have a huge number of user bases. Otherwise, the revenue generated via this model might be meagre. Advantage of keeping In-App advertisements is that the app remains free for all forever. If the ads outweigh the functionality given by the app, soon the app might lose its value.

\subsubsection{In-App Purchases}

These are the ways in which most of the Free Games generate revenue in the current scenario. Games are given freely in the Market, and once the users are immersed and hooked on to the game, it takes a hard turn that users will find difficult to cross unless they buy some consumables like coins or points to proceed further. Similarly, developers give a flavour of how their app will work if you are ready to pay for the features that have been demonstrated. The in-app purchases are of three major types such as purchasing consumables, freemium models and subscription services.

\subsubsection{Data Monetization}

Most of the tech giants are now being questioned on these grounds of Data Monetization, in other words, utilizing users' data. Even though it does not sound great or ethical, it is indeed a legal way of revenue generation. The app may be collecting some information that can be of great value for institutions that might be into research or marketing. The data collected might be used to provide better service to the users in the future etc. Generally, developers collect information such as the device the app is used on, 
location, network, questions, IP address, etc. It is mandatory to inform this publicly to the user via the Privacy Policy and its Terms of Service, etc.

\subsubsection{Crowd Funding}

It is very rare that an app is funded by donations. There are a few Crowdfunding websites such as KickStarter, Indiegogo etc. in which the developers can express their idea about the project and start a campaign to crowdfund that project. People interested in the latest technology and finding your project innovative might come together to support. It is only recommended if you have a great idea which you believe people will support and do not have any other means of support available at your disposal.

\subsubsection{Affiliate Marketing}

Affiliate Marketing is the process of putting an advertisement of another app in yours and getting a commission for every click on that ad, and that gets converted to sales. Lead Generation captures the contact information of the interested users that agree to share the same. In order for this to work, both the apps must be targeted towards the same kind of audience. It is not compulsory to advertise only one particular app, it can be of multiple apps that fall under the same category. Just as with in-app ads, there is no way to predict the revenue that can be generated through this way.

\subsubsection{SMS and Email Marketing}

This is a very traditional way of marketing a product, sending messages and emails to prospective clients so that they are aware of the product. Even though this will not be a sufficient way of marketing, an email can describe or publicise an app with a description of all its features and benefits with images etc. These ways might just help get people to lead to the app without much hassle, but revenue generation through the app still needs to work its way to actually get money out of it.

\subsubsection{Sponsorships}

Just like how some events are sponsored by some companies, apps can also be sponsored so that the funding needed for the app will be taken care by the sponsor. In return to that, ads and offers related to the sponsor need to be integrated into the app, so that the benefit is mutual. Most of the times it will be a company that is involved closely in the area of that app category.

\subsubsection{Paid Apps}

Even though a vast majority of apps on the market are free to download, some apps are upfront paid apps that you need to pay the amount before even installing the app, and all the features are offered to the user without any ads or interruptions further. Even though it is a very simple and useful way of generating revenue, the developer needs to make sure the amount that they pay in order to get a particular feature is worth it.

\section{COST OF APP DEVELOPMENT :}

Calculating the cost of App Development is one of the most important parts of a project proposal. It varies based on a lot of factors which we will discuss now. However, there is a clear difference in the cost when an individual or a freelancer does the app compared to asking an App Development Company to do the same [38]. Both have their own advantages and disadvantages, but we choose based on the context of the app and the customer.

It is not possible to calculate an exact amount as the cost of app development; rather, only an estimate can be drawn based on the requirements given. It is not possible to determine the rate by just taking one factor into consideration and should look for various factors that influence that amount. We will see a few factors that need to be considered before heading for a cost determination [39]. These characteristics determine the worth of the App [25]:

- Functionality/Purpose of the App

- Native or Cross Platform App Development

- Third Party Integrations

- Complexity of the Visual Interface and Code

- Consumption of Hardware Features such as Camera, Bluetooth, NFC, etc.

- Maintenance Plan for the App

The business of Apps website states that a Simple App can be charged anywhere from $\$ 40,000$ to $\$ 60,000$, a Medium Complexity App can be charged anywhere between $\$ 61,000$ to $\$ 120,000$ and a Complex App Development can be in the range of $\$ 120,000+$ in the US. It also states that it would cost 
approximately $\$ 90,000$ per year to have an App Developer on their payroll [39]. The roles of the App Development team can be recognized as Project Manager, Team Lead, Developer, Back End Developer, Designer and Tester. All these roles are needed for an organization that plans on delivering the app, whereas a freelancer will take up apps that are not so complicated that need many work hours to complete the given app. Depending on the complexity of the app, the number of people and work load for each will change, and so does the cost that the app will demand.

\subsection{Cost of App Development in India}

Most of the countries outsource their software development tasks to India since the country has enough resources in the field of software engineering and costs less compared to the counterparts. It will cost less than \$25,000 in India for a Typical App Development, whereas the same would cost more than $\$ 80,000$ in the United States. India has been the most inexpensive destination for any Mobile App development. The following are the reasons why India stands as a pioneer in App Development Globally [36]:

- Developing High Quality Mobile Apps for Nominal and Low Cost

- The time taken for the App Development is quite brief.

- Pool of Well-Experienced Developers

- Updated with all the recent technology and Tools Needed for App Development

- Complete Support for Cross Platform Capabilities

- Maintenance offered is longer and professional

These are just some of the reasons why India is a Mobile App Development Hub for the world. India is constantly growing in the field of app development since many of the universities have kept App Development as a subject or an elective in their curriculum. The majority of the developers in India are Young People and are constantly upgrading their skillset.

\section{SWOC ANALYSIS [40-41]:}

\section{Strengths:}

- Mobile App Development Industry is an Ever-Growing Industry with billions of users getting added every year.

- Preferred over websites and other software because of the ease of usage and availability in handheld devices.

- Huge User Base Covered because of the wide-spread availability

- All companies are now dependent on an app to reach a wider audience and get recognized quickly

- Symbol of Quality and Status for a company to have its app on the market

- Targets Global Audience instantly

\section{Weakness:}

- Varied Hardware Configurations available cannot target a group of devices alone.

- Native Development may not be feasible because of a larger market share of Android and iOS.

- Complete Guarantee of app execution is not possible.

- Development costs are higher than traditional Website Development costs.

- Very Competitive market [42]

- Performance is dependent on the target device

- Concerns over Security in Older Devices

- Revenue Generation may not be successful for apps with less user base.

\section{Opportunities:}

- A lot of people are moving from applications and websites to mobile apps to do their daily tasks.

- A huge demand for apps is constantly growing in the current market [18]

- Can attract a larger and wider group of audience in a short span 
- Expansion of the app to provide more and more functionalities

- Personalization of apps makes every app unique to its user

- Marketing for a new app is easy since the user base is already established.

\section{Challenges:}

- Revenue Generation is not so easy unless the ground work is done properly in that specific area.

- Modded or Cracked Apps availability risks loss in revenue generation

- Development needed in various Platforms makes it difficult to give a tailored experience [4].

- Installation of the apps via any other mode except official app stores will not be indexed or supported

- Securing App and user data might be an issue since most phones have finger print and face detection as ways of authenticating [23].

- Limited budgets to develop apps

- Marketing and Maintenance Costs

\section{FUTURE OF APP DEVELOPMENT INDUSTRY POST COVID :}

Mobile apps have been on a constant rise since the pandemic, and since people are stuck at home and have nowhere to go, it has been a virtual world in which people have immersed themselves. A lot of people are trying out new apps from the app stores and experimenting to find a game, a tool, a social network to see what is what. At a time where we all are bound by restrictions everywhere; mobile apps came to the rescue by keeping our work progress. Enterprise apps have kept our work going and social network apps have kept our near and dear ones closer. Delivery apps have kept all our needs satisfied and Food Delivery apps have worked to make sure we get any food we like to our doorsteps.

The world post this pandemic will not let down their mobile phones anytime soon, and so the Mobile App Development Industry needs to leverage this situation to the maximum by constantly finding innovation in the ways of app development and delivery. The Pandemic has made everyone realize the advantage of these mobile apps. It is very evident that it is going to grow in leaps and bounds in the future. In order to keep the customers satisfied and keep the trend that is catching on in the industry, we need to focus on some emerging technologies that need to be taken care of post this pandemic. Let us see a few of them in brief:

\subsection{Artificial Intelligence (AI)}

This pandemic has brought forth a complete digital uprising towards which the world was moving slowly towards. AI is not new to the mobile app world, but it has begun to make a name for itself by inserting itself into services like Banking, Online Shopping, Music, Finance, etc. People are now very familiar with AI-BASED assistants like Siri, Google Assistant, Alexa etc. They are getting used to these assistants as a part of their life. Chatbots in various websites have started as a means of getting immediate communication and prompt answers to frequently asked questions. There is a plethora of amazing things bound to happen when AI is combined with the Internet of Things, Cloud Computing and Block Chain.

\subsection{AR/VR}

Mobile Apps can utilize the concept of AR and VR to make the experience of games a more realistic and enjoyable one. Retail apps can use AR/VR to give tailored experience to the users like Optical, Dressing, Interior Design, Furnitures. It can be a very engaging and interesting one if used in the field of education to take online classes. In the area of healthcare, AR/VR can play a major role in diagnosing, treating and empowering the healthcare workers. AR/VR based digital interactions can take the customers experience with an app to the next level.

\subsection{Beacon Technology}

Beacon Technology is becoming increasingly popular among the recent trends that are taken by the healthcare industry, shopping and hotels, etc. Customers normally would like to receive personalized offers and discounts and see what people in closer proximity are targeting. In the hospitality area, apps 
can use Beacon to enhance the experience of checking in or checking out, Security Checks and getting essential information about the vacancy of the rooms. Event-based apps can also automate check-in and out, navigations, registrations, etc. Sports based apps will help in managing audience experience, seat locating, stall locating, upselling tickets, promotions, real-time information, etc. It will be a game changer in the future of a post-pandemic world.

\section{CONCLUSION :}

The Mobile App Development Industry is a Young Player in the market and has already crossed the revenue that other IT or IT Enabled Industry has procured. This Industry has evolved and grown drastically in a short period of time and has got people who would have never thought of using software in their entire life and are now experts in using a Smart Phone and all the essential Apps that the phone has to offer. It is safe to say that a Mobile Phone is now not only used for its actual purpose of calling and sending SMS but a lot more than that [43]. The number of new users joining Apple or Google to activate a new device is constantly growing every day. India has taken advantage of this industry to put itself as a country of fast-growing App Users and App Developers in the world. Apart from that, India has also contributed to be the third largest country from which the revenue from apps have been phenomenal. This industry has made way for India to be a world leader in not just consuming apps, but also developing them. India has also become a preferred country to invest in app development globally. We have discussed in detail how this industry is and will be. Since we cannot see a decline in the usage of mobile phones in our day-to-day life, we can also be sure that the App Development Industry is going to thrive in the upcoming days. If it focuses on utilizing the recent trends in IT appropriately and delivering Apps that are not going to be just a remake of existing apps, then the Mobile App Development Industry will keep growing in the upcoming years.

\section{REFERENCES :}

[1] Mobile Operating System Market Share Worldwide. (n.d.). Retrieved May 3, 2021, from https://gs.statcounter.com/os-market-share/mobile/worldwide

[2] Mobile Operating System Market Share United States of America. (2021, March). Retrieved May 11, 2021, from https://gs.statcounter.com/os-market-share/mobile/united-states-of-america

[3] Rakestraw, T. L., Eunni, R. V., \& Kasuganti, R. R. (2013). The mobile apps industry: A case study. Journal of Business Cases and Applications, 9(1), 1-26.

[4] Joorabchi, M. E., Mesbah, A., \& Kruchten, P. (2013). Real Challenges in Mobile App Development. 2013 ACM / IEEE International Symposium on Empirical Software Engineering and Measurement. Published. https://doi.org/10.1109/esem.2013.9

[5] Vallon, R., Wenzel, L., E. Brüggemann, M., \& Grechenig, T. (2015). An Agile and Lean Process Model for Mobile App Development: Case Study into Austrian Industry. Journal of Software, 10(11), 1245-1264. https://doi.org/10.17706//jsw.10.11.1245-1264.

[6] Peek, S. (2020, July 9). What Is Mobile App Development? Retrieved May 11, 2021, from https://www.businessnewsdaily.com/5155-mobile-app-development.html

[7] Raluca Budiu. (2016, January 19). Mobile: Native Apps, Web Apps, and Hybrid Apps. Retrieved May 11, 2021, from https://www.nngroup.com/articles/mobile-native-apps/

[8] Janani. (2021, February 11). Different Types of Mobile Application Development- Every Business Owner Must Know! Retrieved May 11, 2021, from https://www.zuantechnologies.com/blog/different-types-mobile-application-development-everybusiness-owner-must-know/

[9] Valdellon, L. (2020, November 2). What Are the Different Types of Mobile Apps? And How Do You Choose? Retrieved May 11, 2021, from https://clevertap.com/blog/types-of-mobile-apps/

[10] Zohud, T., \& Zein, S. (2021). Cross-Platform Mobile App Development in Industry: A Multiple Case-Study. International Journal of Computing, 46-54. https://doi.org/10.47839/ijc.20.1.2091 
[11] Design Rush. (2020, November 27). The Ultimate Guide to Hybrid App Development. Retrieved May 11, 2021, from https://www.designrush.com/trends/hybrid-mobile-app-development

[12] Mobile Application Market Size, Share \& Growth| Industry Analysis, 2026. (n.d.). Retrieved May 11, 2021, from https://www.alliedmarketresearch.com/mobile-application-market

[13] Michael Mandel, \& Elliott Long. (2019, September). The App Economy in India. Progressive Policy Institute. Retrieved from https://www.progressivepolicy.org/wpcontent/uploads/2019/09/PPI_IndianAppEconomy_V3-1.pdf

[14] Top App Development Companies (2021). (2021b, May 10). Retrieved May 11, 2021, from https://www.businessofapps.com/app-developers/india/

[15] App Development Industry in India \& its Dynamics. (2019, November 26). Retrieved May 11, 2021, from https://www.insightssuccess.in/app-development-industry-india-dynamics/

[16] Yan, H., Wang, J., Wang, Y., \& Zhou, X. (2017). An Example for Industry 4.0: Design and Implementation of a Mobile App for Industrial Surveillance Based on Cloud. $20175^{\text {th }}$ International Conference on Enterprise Systems (ES). Published. https://doi.org/10.1109/es.2017.61

[17] Menon, N. G. (2019, September 26). What Are the Various Phases of Mobile App Development? Retrieved May 11, 2021, from https://www.cognitiveclouds.com/insights/what-are-the-variousphases-of-mobile-app-development/

[18] Jabangwe, R., Edison, H., \& Duc, A. N. (2018). Software engineering process models for mobile app development: A systematic literature review. Journal of Systems and Software, 145, 98-111. https://doi.org/10.1016/j.jss.2018.08.028

[19] Busch, Z. (2019, June 26). 6 Stages of the Mobile Development Lifecycle. Retrieved May 11, 2021, from https://learn.g2.com/mobile-development-lifecycle

[20] Wikipedia contributors. (2021, April 23). Website wireframe. Retrieved May 11, 2021, from https://en.wikipedia.org/wiki/Website_wireframe

[21] Ian Blair. (n.d.-a). 8 Steps to Understanding the Mobile App Development Lifecycle. Retrieved May 11, 2021, from https://buildfire.com/understanding-mobile-app-development-lifecycle/

[22] Mobile Backend-as-a-Service - 4 mBaaS Platforms you need to check out. (2019, July 26). Retrieved May 11, 2021, from https://waracle.com/blog/mbaas/how-to-choose-the-right-backendas-a-service-baas-platform/

[23] Francese, R., Gravino, C., Risi, M., Scanniello, G., \& Tortora, G. (2017). Mobile App Development and Management: Results from a Qualitative Investigation. 2017 IEEE/ACM $4^{\text {th }}$ International Conference on Mobile Software Engineering and Systems (MOBILESoft). Published. https://doi.org/10.1109/mobilesoft.2017.33

[24] Zhang, M., Cheow, E., Ho, C. S., Ng, B. Y., Ho, R., \& Cheok, C. C. S. (2014). Application of Low-Cost Methodologies for Mobile Phone App Development. JMIR MHealth and UHealth, 2(4), e55. https://doi.org/10.2196/mhealth.3549

[25] K. Flora, H., Wang, X., \& V.Chande, S. (2014). An Investigation into Mobile Application Development Processes: Challenges and Best Practices. International Journal of Modern Education and Computer Science, 6(6), 1-9.

[26] Jones, N., \& Moffitt, M. (2016). Ethical guidelines for mobile app development within health and mental health fields. Professional Psychology: Research and Practice, 47(2), 155-162.

[27] Asfour, A., Zain, S., Salleh, N., \& Grundy, J. (2019). Exploring agile mobile app development in industrial contexts: A qualitative study. International Journal of Technology in Education and Science, 3(1), 29-46.

[28] Holzer, A., \& Ondrus, J. (2009). Trends in Mobile Application Development. Lecture Notes of the Institute for Computer Sciences. Social Informatics and Telecommunications Engineering, 55-64. https://doi.org/10.1007/978-3-642-03569-2_6. 
[29] Enabling the new normal - mobile app development in the COVID-19-Era. (2020, July 14). Retrieved May 11, 2021, from https://www.businessofapps.com/insights/mobile-appdevelopment-in-the-covid-19-era/

[30] Statista. (2021, February 4). Annual number of global mobile app downloads 2016-2020. Retrieved May 11, 2021, from https://www.statista.com/statistics/271644/worldwide-free-andpaid-mobile-app-store-downloads/

[31] Holzer, A., \& Ondrus, J. (2010). Mobile Application Market: A Mobile Network Operators' Perspective. Lecture Notes in Business Information Processing, 186-191. https://doi.org/10.1007/978-3-642-17449-0_19

[32] Ian Blair. (n.d.-b). Mobile App Download and Usage Statistics (2021). Retrieved May 11, 2021, from https://buildfire.com/app-statistics/

[33] Statista. (2021b, February 4). Leading Android app categories worldwide 2019. Retrieved May 11, 2021, from https://www.statista.com/statistics/200855/favourite-smartphone-app-categories-byshare-of-smartphone-users/

[34] Wilcox, M. (2013, March 1). How Much Is an Active User Worth? Retrieved May 11, 2021, from https://www.developereconomics.com/blog/how-much-is-an-active-user-worth/

[35] Miller, B. (2020, March 20). ARPU: How to Calculate Average Revenue Per User. Retrieved May 11, 2021, from https://clevertap.com/blog/arpu-everything-you-need-to-know-about-averagerevenue-per-user/

[36] Harnil Oza. (2020). Indian App Development Industry Report 2021. Retrieved May 11, 2021, from https://www.hyperlinkinfosystem.com/research/indian-app-development-industry-report-2020

[37] Mobile Action Team. (2020, October 30). 8 Proven App Revenue Models for Your Mobile App. Retrieved May 11, 2021, from https://www.mobileaction.co/blog/app-business/app-revenuemodels/

[38] Top App Development Companies (2021). (2021a, May 10). Retrieved May 11, 2021, from https://www.businessofapps.com/app-developers/

[39] App Development Cost (2021). (2021, March 26). Retrieved May 11, 2021, from https://www.businessofapps.com/app-developers/research/app-development-cost/

[40] Aithal, P. S., \& Kumar, P. M. (2015). Applying SWOC Analysis to an Institution of Higher Education. International Journal of Management, IT and Engineering, 5(7), 231-247.

[41] Madhushree, R. R., Kumar, A., \& Aithal, P. S. (2018). Business strategy of top Indian IT company: Mindtree. International Journal of Case Studies in Business, IT and Education (IJCSBE), 2(1), 2236.

[42] Kornilova, V. (2016, September 15). Perfect SWOT Analysis for Mobile App. How to Validate Your Ideas. Retrieved May 11, 2021, from https://theappsolutions.com/blog/marketing/swot-formobile-app/

[43] McCandless, N. (2015, December 9). The Future of The Mobile App Industry. Retrieved May 11, 2021, from https://theappcompany.com/the-future-of-the-mobile-app-industry/ 